Original article

\title{
The effect of intrauterine hypoxia on testicular reproductive function
}

\author{
Tatiana V. Palatova, Alla B. Bucharskaya, Anna V. Medvedeva, Elena S. Voronina, Svetlana S. Pakhomy, \\ Galina N. Maslyakova
}

Saratov State Medical University, Saratov, Russia

Received 18 May 2020, Revised 3 November 2020, Accepted 21 April 2021

(C) 2020, Palatova T.V., Bucharskaya A.B., Medvedeva A.V., Voronina E.S., Pakhomy S.S., Maslyakova G.N.

(C) 2020, Russian Open Medical Journal

\begin{abstract}
Goal - to assess the effect of antenatal hypoxia of various origins on the morphology and reproductive function of the testes of newborn and mature rats in experiment.

Material and Methods - In experiments 15 white outbred female rats aged 4 to 10 months with a weight of $200 \pm 30 \mathrm{~g}$ were used. Laboratory animals were randomly divided into 2 experimental and 1 control groups, 5 females each. The first group underwent normobaric hypoxia throughout pregnancy (21 days). Hypoxia modeling was conducted in accordance with the method of N.N. Karkishchenko (2010). The second group underwent hemic hypoxia during the second and third week of pregnancy, in accordance with the method of L.M. Sosedova (2012). The third (control) group was not exposed to any effect throughout pregnancy.

Results - in the testicles of newborn rats of the experimental groups, the decrease of tubule diameter was observed, the increase of stroma area and development of interstitial edema were noted. In the group of hemic hypoxia, a significant decrease in the number of Leydig cells was noted. In the tissues of the testicles of mature rats, who underwent antenatal hypoxia, a decrease of tubule diameter, a significant decrease in the spermatogenesis index and a decrease of spermatogonia number were noted. The developed damage of spermatogenic epithelium in experimental groups of newborns and mature rats was confirmed by marked expression of the apoptosis marker (Bax), weak expression of proliferation markers (Ki-67) and receptor of receptor of fibroblast growth factor (FGFR).

Conclusion - in animals with chronic hypoxia of various origins, there is an inhibition of spermatogenesis and a violation of the spermatogenetic function of the testicular seminiferous tubules.
\end{abstract}

Keywords: testis, male infertility, antenatal hypoxia, receptor of fibroblast growth factor.

Cite as Palatova TV, Bucharskaya AB, Medvedeva AV, Voronina ES, Pakhomy SS, Maslyakova GN. The effect of intrauterine hypoxia on testicular reproductive function. Russian Open Medical Journal 2021; 10: e0204.

Correspondence to Tatyana V. Palatova. Address: 112, Bolshaya Kazachya str., Saratov, 410012, Russia. Phone: +7-8452-669748. E-mail: iamnot88@bk.ru.

\section{Introduction}

Infertility is a severe pathology that affects about 70 million people worldwide. The World Health Organization (WHO) estimates that $9 \%$ of couples worldwide struggle with fertility problems, with $50 \%$ being male infertility [1].

The endocrine system of the fetus, including the testicular, is formed in utero from 8-9 weeks of the gestational period and is exposed to various damaging factors. Morphogenesis of the endocrine system of the fetus determines the adaptive reactions of the body in postnatal life, its features can underlie the pathogenesis of endocrine diseases of an adult, including the pathogenesis of male infertility.

Fetal hypoxia is one of the most common complications of pregnancy and childbirth [2]. However, at present, the role of hypoxia in the development of the reproductive system of the fetus remains controversial $[2,3]$.

It is difficult to carry out a comparative analysis in dynamics on clinical material; therefore an attempt was made to simulate variants of intrauterine hypoxia and to study its effect on the reproductive system in an experimental model.
Goal of the study - to assess the effect of antenatal hypoxia of various origins on the morphology and reproductive function of the testes of newborn and mature rats in experiment.

\section{Material and Methods}

\section{Study design}

The experimental study, of the effect of chronic hypoxia on the development of the testes in the offspring of rats during the neonatal and puberty period was carried out. In a previously published work [4], we investigated the effect of normobaric hypoxia on the development of the gonads in rat fetuses. In the present study, we expanded the scope of work and studied the effect of normobaric and hemic hypoxia on testicular development in the offspring of rats during the neonatal period, as well as in mature rats.

The Manual on experimental (preclinical) study of new pharmacological substances [5] and "The guide to laboratory animals and alternative models in biomedical researches" [6] were based on the development of the experimental research model. Work with laboratory animals was conducted in accordance with 
the Geneva Convention on the "International Principles of Biomedical Research using Animals" (1985) and the Helsinki Declaration (2000) on the humane attitude to animals.

The experiment was performed on 15 healthy white male rats weighing $180-260 \mathrm{~g}$, obtained from the vivarium of the Saratov State Medical University $\mathrm{n}$ a V.I. Razumovsky. Animals received a standard diet once a day, with free access to water. Animals were randomly divided into 2 experimental and 1 control groups, 5 females each. The first group underwent normobaric hypoxia throughout pregnancy (21 days). Hypoxia modeling was carried out in accordance with the method of N.N. Karkishchenko (2010) [6]. The animals of the experimental group were placed under a glass cover and stayed there until symptoms of hypoxia (frequent intermittent breathing, passive state) became visible. This experiment was conducted daily until the onset of labor. The second group underwent hemic hypoxia during the second and third week of pregnancy, in accordance with the method of L.M. Sosedova (2012) [7]. From the 10th to the 19th day of pregnancy, rats were injected daily with a sodium nitrite solution at a dose of $50 \mathrm{mg} / \mathrm{kg}$. The third (control) group was not exposed to any effect throughout pregnancy. The timing of pregnancy began when spermatocytes were found in the vaginal smears of rats.

After delivery, there were 91 individuals in the litter, 27 in the first group, 11 of them males, 29 in the second, 10 of them were males, only 35 were in the control group, 18 of which were males. To study the effect of chronic intrauterine hypoxia in the longterm period, 5 males were selected from each group. All individuals were kept under standard vivarium conditions until maturity (90 days). At the onset of puberty, male rats were removed from the experiment by decapitation. The remaining 55 newborn pups were withdrawn from the experiment by cervical dislocation.

\section{Morphological study}

The testicles of rats were fixed in buffered neutral $10 \%$ formalin; dehydrated in a battery of alcohols of ascending concentration, poured into paraffin. Sections of testicles 4 to $5 \mu \mathrm{m}$ thick were placed on objective glasses and dewaxed according to the conventional standard procedure. Sections were stained with hematoxylin and eosin and used for immunohistochemical (IHC) staining.

In ten fields of view of each case in the testicles, the following parameters were counted: the number of tubules, the number of cells in the tubules, the number of vessels in the stroma, the number of Leydig cells, the diameter of the tubules, the area of the parenchyma and stroma. The following signs were determined in the tissues of the testicles of mature rats: tubule diameter, number of spermatogonia, spermatogenesis index, which is the ratio of the number of layers of spermatogenic cells found in each convoluted seminiferous tubule to the number of calculated tubules. Morphometric analysis of histological preparations was performed using a Microvizor of medical transmitted light $\mu$ Vizo101 (LOMO).

\section{Immunohistochemical (IHC) method}

After dewaxing and rehydration of paraffin sections, an IHC study was performed according to the immunohistochemical staining protocol. As a visualization system, REVEAL-Biotin-Free Polyvalent DAB (Spring Bioscience, USA) was used. REVEALBiotin-Free Polyvalent DAB kit (Spring Bioscience, USA) was used as the detection system, and diaminobenzidine (DAB) was used as the chromogen. The following antibodies of Abcam (UK) were used in the work: Monoclonal Rabbit Anti- Ki67 (1:100 dilution); Monoclonal Mouse anti Bax antibody (1:50 dilution), Polyclonal Antibody to Receptor of fibroblast growth factor 2 (1:10 dilution).

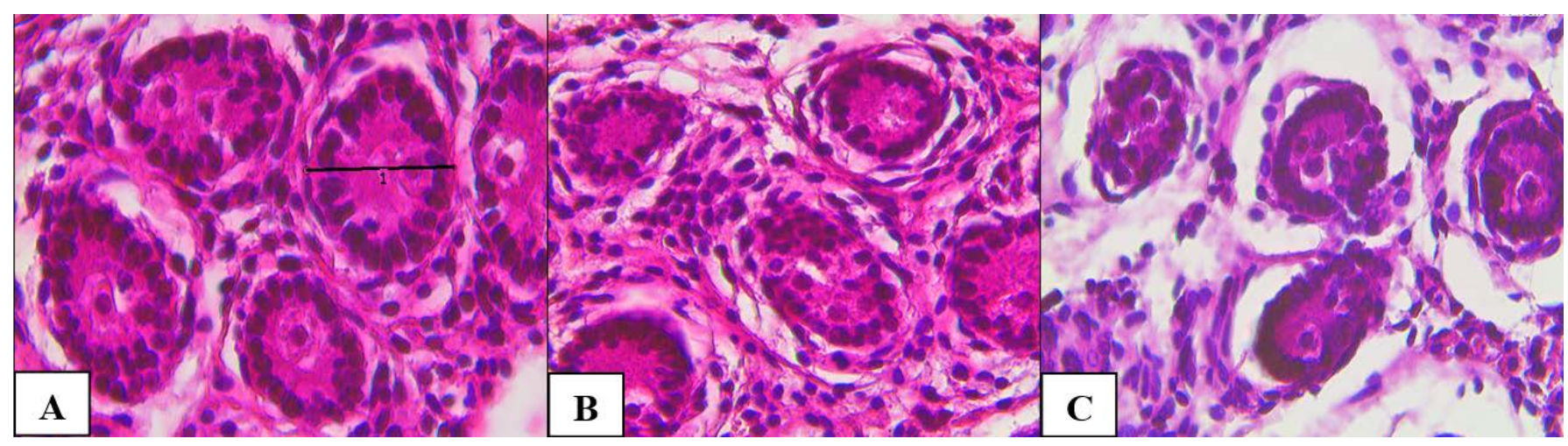

Figure 1. Testicular tissue of newborn rat pups. A - control, B - normobaric hypoxia, C - hemic hypoxia. Hematoxylin and eosin, $x 774$.

Table 1. Morphological characteristics of the testicles in newborn rats

\begin{tabular}{|c|c|c|c|c|}
\hline Quantitative characteristics (in $f / v \times 774$ ) & $\begin{array}{l}\text { 1st group (normobaric hypoxia), } \\
n=6 \mathrm{Me}[25 ; 75]\end{array}$ & $\begin{array}{l}\text { 2nd group (hemic hypoxia), } \\
n=5 \text { Me }[25 ; 75]\end{array}$ & $\begin{array}{c}3 d \text { group (control), } \\
n=13 \mathrm{Me}[25 ; 75]\end{array}$ & Pvalue \\
\hline Diameter of tubules, $\mathrm{mm}$ & $0.043[0.035 ; 0.046]$ & $0.026[0.025 ; 0.03]$ & $0.05[0.046 ; 0.053]$ & $0.186^{*}<0.001 * *<0.001 * * *$ \\
\hline The number of tubules & $3[2 ; 3]$ & $5[4 ; 6]$ & $4[3 ; 5]$ & $<0.001 * 0.003 * * 0.003 * * *$ \\
\hline The number of cells in the tubules & $21[19 ; 27]$ & $20[17 ; 26]$ & $23[19 ; 28]$ & $0.03 * 0.276 * * 0.276 * * *$ \\
\hline Number of vessels & $4[3 ; 4]$ & $1[0 ; 1]$ & $2[1 ; 3]$ & $0.016 * 0.003 * * 0.003 * * *$ \\
\hline The number of Leydig cells & $13[11 ; 20]$ & $8[6 ; 9]$ & $11[9 ; 17]$ & $0.221 * 0.225 * * 0.001 * * *$ \\
\hline Area of tubules, mm2 & $0.0111[0.0099 ; 0.0116]$ & $0.0065[0.006 ; 0.0071]$ & $0.012[0.011 ; 0.013]$ & $0.049 *<0.001 * * 0.001 * * *$ \\
\hline Stroma area, $\mathrm{mm} 2$ & $0.0105[0.01 ; 0.0313]$ & $0.0145[0.0139 ; 0.015]$ & $0.009[0.0071 ; 0.01]$ & $0.009 *<0.001 * * 0.027 * * *$ \\
\hline
\end{tabular}

* - $\mathrm{P}$ value at comparison of control group and normobaric hypoxia; ** $-\mathrm{P}$ value at comparison of $\mathrm{r}$ control group and hemic hypoxia; *** $-\mathrm{P}$ value at comparison of normobaric and hemic hypoxia. 
Table 2. Expression of immunohistochemical markers of the testicles in newborn rats.

\begin{tabular}{lccc}
\hline \multirow{2}{*}{ Marker } & Hypoxia, $n=11$ & Control, $n=13$ & $\varphi$ \\
& Me $[25 ; 75]$ & Me $[25 ; 75]$ & criterion \\
\hline Proliferation Marker (Ki67) & $62[54 ; 77]^{*}$ & $78.5[75 ; 82]^{*}$ & 2.489 \\
Apoptosis Marker (Bax) & $64[50 ; 66]^{*}$ & $23.5[21 ; 43]^{*}$ & 6.046 \\
Receptor of fibroblast growth & $10[0 ; 15]^{*}$ & $34[32 ; 41]^{*}$ & 4.25 \\
\hline factor (FGFR) & & \\
\hline
\end{tabular}

$\phi^{*}$ is the empirical value of the Fisher test

Evaluation of immunohistochemical reactions was based on a visual assessment of the staining intensity and counting the number of immunopositive (positive) cells.

\section{Statistical analysis}

In the statistical analysis of the results, we used IBM SPSS Statistics 24.0, Microsoft Office Excel 2007 software packages. When checking the sample sets of the studied quantities for the normality of the distribution by the Kolmogorov-Smirnov method, it was found that the distribution of the studied parameters is different from the normal one, therefore, for comparative analysis, non-parametric statistics methods were used with calculation of the median, interquartile range, significance levels of differences between groups according to the Mann-Whitney criterion and Fisher. Differences were considered statistically significant at $p<0.05$.

\section{Results}

\section{Morphological characteristics of the testicles in newborn rats}

During a light microscopy survey of testicular tissue of the control group, a thick connective tissue capsule was determined from the outside. The convoluted seminiferous tubules had an oval and rounded shape. Cells in the tubules were located randomly, there was no clearance. A soft-fibrous connective tissue was located between the tubules (Figure 1A). Under microscopy of testicular tissue of the 1st experimental group (normobaric hypoxia), the morphological picture did not differ significantly. Individual spermatogenic epithelial cells were vacuolated. Some sparseness of the tubular apparatus due to fibrosis and peritubular edema was noted (Figure 1B). In testicular tissue of the 2nd experimental group (hemic hypoxia), the tubules were reduced, marked stromal edema was noted, the basement membrane of individual tubules was fragmented and fuzzy. Some fields of view were represented only by stromal component tubules were absent (Figure $1 \mathrm{C}$ ). Morphometric indicators are shown in Table 1.

According to the results of the non-parametric Mann-Whitney test, significant differences were revealed between the 1st and 3rd groups according to the following parameters: tubule area, stroma area, number of tubules in the field of view. When comparing hemic hypoxia with the control, significant differences were revealed in such parameters as the diameter of the tubules, the area of the tubules and the area of the stroma, the number of tubules, the number of vessels, and the number of Leydig cells.

An immunohistochemical study, in the control group showed pronounced expression of proliferation marker expression (Ki-67), a weak expression of apoptosis marker reaction (Bax) and moderate expression of receptor of fibroblast growth factor (FGFR). In both experimental groups, weak expression of the proliferation marker was observed, moderate expression of the apoptosis marker, expression of receptor of fibroblast growth factor was not observed or was weak. According to the results of the non-parametric Fisher test, significant differences in the groups were observed with the expression of a proliferation marker (Ki67), apoptosis marker (Bax), receptor of fibroblast growth factor (FGFR). Data on the percentage of expressing cells in groups and significant differences are presented in Table 2.

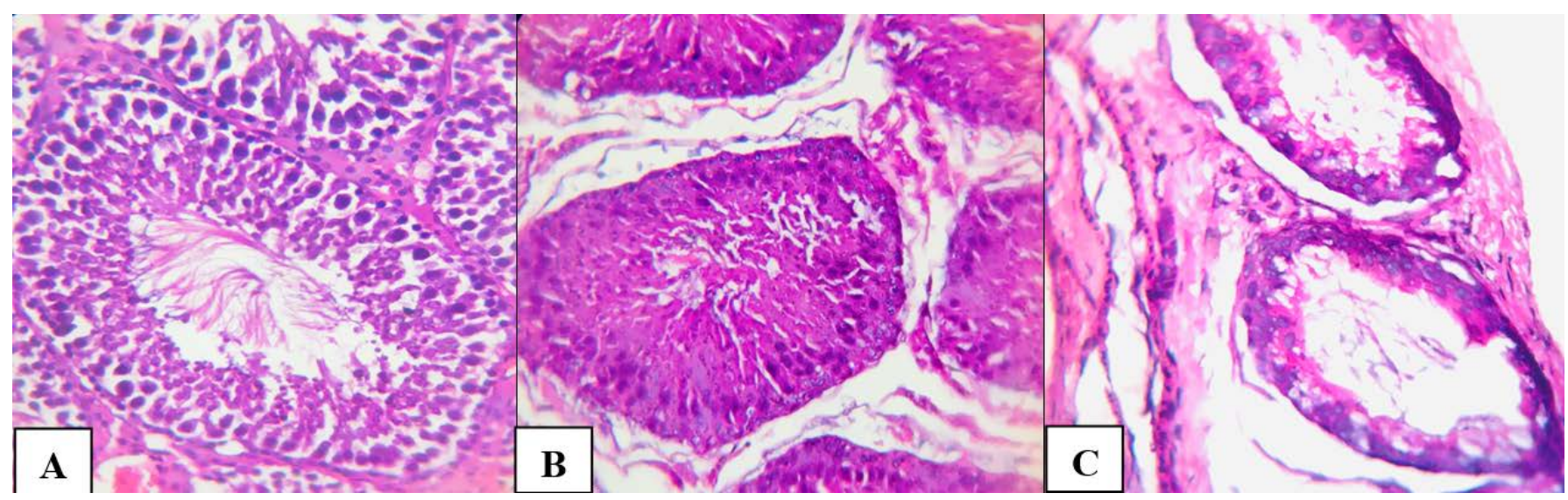

Figure 2. Testicular tissue of adult rats. A - control, B - normobaric hypoxia, C-hemic hypoxia. Hematoxylin and eosin. X246.4.

Table 3. Morphological characteristics of the testicles in mature rats

\begin{tabular}{lccc}
\hline Indicators, in $f / v, x 246.4$ & $\begin{array}{c}\text { 1st group (Normobaric } \\
\text { hypoxia), } n=5 \text { Me }[25 ; 75]\end{array}$ & $\begin{array}{c}\text { 2st group (Hemic hypoxia), } \\
n=5 \text { Me }[25 ; 75]\end{array}$ & $\begin{array}{c}\text { 3st group (Control), } \\
n=5 \text { Me [25;75] }\end{array}$ \\
\hline Diameter of tubules, mm & $0.2105[0.2 ; 0.22]^{*}$ & $0.159[0.151 ; 0.173]^{*}$ & $0.2375[0.21 ; 0.254]^{*}<0.001^{*}<0.001^{* *}<0.001^{* * *}$ \\
The number of spermatogonia in the tubule & $58[48 ; 63]^{*}$ & $47[38 ; 51]^{*}$ & $56[53 ; 69]^{*}$ \\
Spermatogenesis Index, units & $3[3 ; 4]^{*}$ & $3[3 ; 4]^{*}$ & $0.001^{*} 0.001^{* *} 0.006^{* * *}$ \\
\hline
\end{tabular}

$*$ - $\mathrm{P}$ value at comparison of control group and normobaric hypoxia; ** $-\mathrm{P}$ value at comparison of control group and hemic hypoxia; $* * *-\mathrm{P}$ value at comparison of normobaric and hemic hypoxia. 


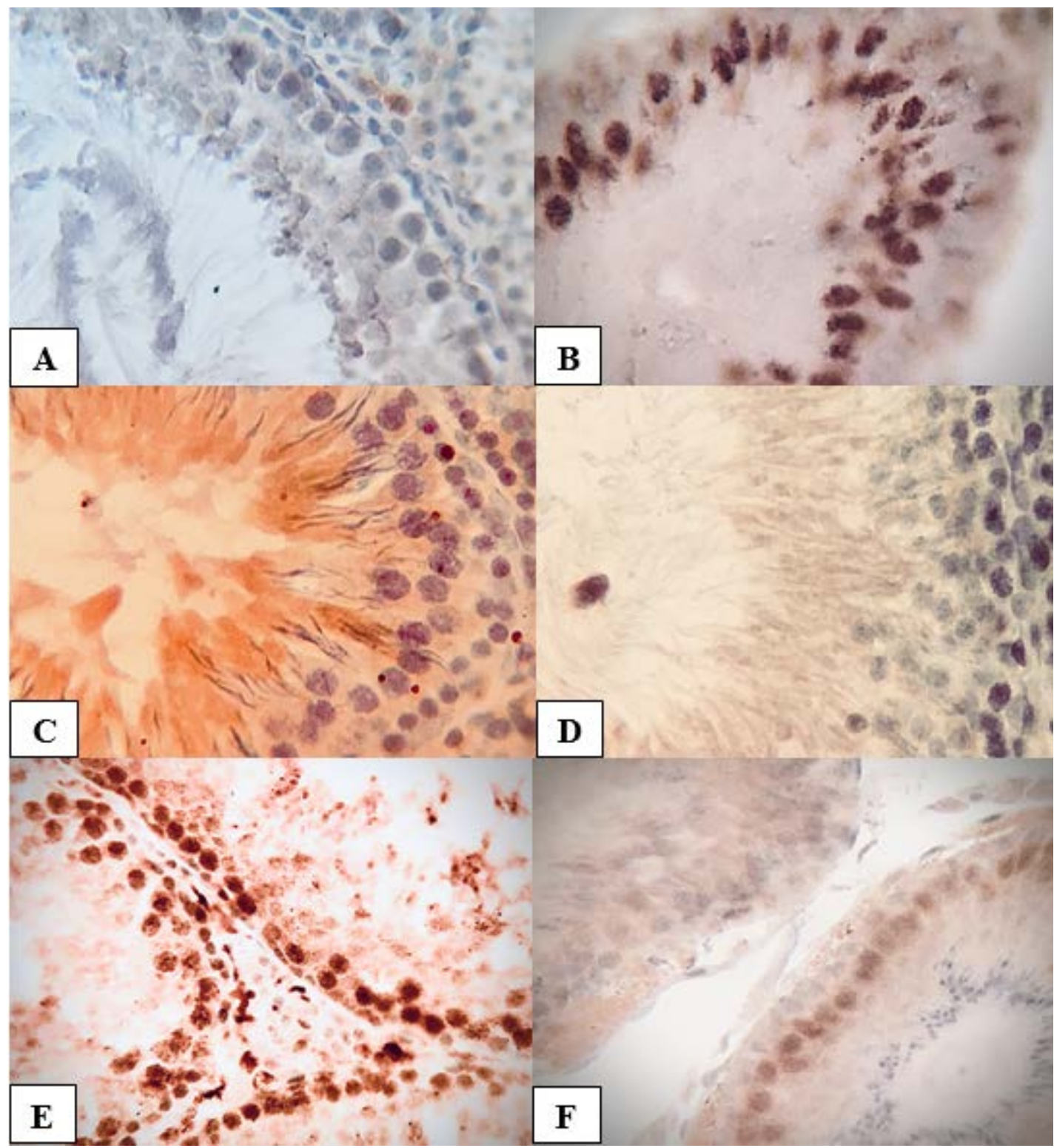

Figure 3. IHC study of testicular tissue of mature males. x 40. A, B - with apoptosis marker Bax (A - control, B - hemic hypoxia); C, D - with receptor of fibroblast growth factor FGFR. (C - control, D - normobaric hypoxia); E, F- with a proliferation marker Ki67 ( $E$ - control, F- normobaric hypoxia).

Table 4. Expression of immunohistohemical markers of the testicles in mature rats

\begin{tabular}{|c|c|c|c|c|}
\hline \multirow{2}{*}{ Marker } & \multicolumn{2}{|c|}{ Hypoxia Me $[25 ; 75]$} & \multirow{2}{*}{$\begin{array}{c}\text { 3st group (Control), } \\
n=5 \mathrm{Me}[25 ; 75]\end{array}$} & \multirow{2}{*}{$\varphi$ criterion } \\
\hline & 1st group (normobaric), $\mathrm{n}=5$ & 2 st group (hemic), $n=5$ & & \\
\hline Proliferation Marker (Ki67) & $30.5[28 ; 33]^{*}$ & $25[17 ; 30]^{*}$ & $53.5[49 ; 57]^{*}$ & $3.338 * 4.13 * * 0.792 * * *$ \\
\hline Apoptosis Marker (Bax) & $25[20 ; 39]^{*}$ & $80[77 ; 86]^{*}$ & $11[8 ; 15]^{*}$ & $2.623 * 10.875 * * 8.252 * * *$ \\
\hline
\end{tabular}

${ }^{*}-\varphi$ value for control group and normobaric hypoxia; ${ }^{* *}-\varphi$ value for control group and hemic hypoxia; ${ }^{* *}-\varphi$ value for normobaric and hemic hypoxia.

\section{Morphological characteristics of the testicles in mature rats}

In control group, the testicle was surrounded by a dense protein membrane consisting of collagen and elastic fibers, which were located between which fibroblasts and fibrocytes. The convoluted seminiferous tubules had a round, oval and polygonal shape (Figure $2 \mathrm{~A}$ ). The diameter of the tubules ranged from 0.21 to $0.25 \mathrm{~mm}$ (median $0.23 \mathrm{~mm}$ ). In the lumen of the tubules, on the basement membrane, there were sustentocytes and spermatogenic cells at various stages of differentiation. Almost all of the seminiferous tubules contained cells of the germinogenic epithelium at all stages of maturation, including spermatocytes. The number of spermatogonia in one tubule ranged from 53 to 69 (median 56 in the tubule). The spermatogenesis index was 4 (Table 3). 
In the first experimental group (normobaric hypoxia), foci of destruction of the basement membrane, interstitial edema, degenerative changes in spermatogenic epithelium, and karyopicnosis were noted. The diameter of the tubules fluctuated slightly, the median was $0.21 \mathrm{~mm}$. The number of spermatogonia varied from 48 to 63 (median 47 in one tubule), the spermatogenesis index was 3 units.

In the second experimental group (hemic hypoxia), an increase in pathological changes was noted: the diameter of the convoluted tubules was reduced, and in the part of spermatogonia, dystrophic changes in the form of vacuolization of the cytoplasm. In some tubules, inhibition of spermatogenesis was observed (Figure 2C). During morphometric analysis, the diameter of the tubules ranged from 0.151 to 0.173 (median $0.159 \mathrm{~mm}$ ), the number of spermatogonia ranged from 38 to 51 (median 47), and the spermatogenesis index was 3 (Table 3 ).

According to the results of the non-parametric Mann-Whitney test, significant differences were found in both experimental groups and the control in all parameters. When comparing the experimental groups with each other, significant differences were observed in such parameters as the number of spermatogonia, the diameter of the tubules $(p \leq 0.05)$. An immunohistochemical study of testicular tissue of mature rats of the control group showed pronounced expression of the proliferation marker (Ki67) in spermatogonia, weak expression of the apoptosis marker (Bax) in individual spermatogonia, and moderate expression of receptor of fibroblast growth factor in spermatozoa (Figure 3). In the experimental groups, the expression of the proliferation marker was weak, in the group of hemic hypoxia in the epithelial cells of individual tubules, expression was not observed. Expression of the apoptosis marker (Bax) was different in the experimental groups. So, in the group with experimental normobaric hypoxia, the expression of the apoptosis marker (Bax) was weakly and moderately expressed in the epithelial cells of individual tubules. In the group with hemic hypoxia, expression was nuclear, pronounced and was observed in all spermatogenous epithelial cells (Figure 3). The expression of receptor of fibroblast growth factor was weak in both experimental groups (Table 4).

According to the results of the non-parametric Fisher test, significant differences in the experimental and control groups were observed in the expression of a proliferation marker (Ki67), apoptosis marker (Bax), receptor of fibroblast growth factor (FGFR). When comparing the experimental groups with each other, significant differences were observed in the expression of apoptosis marker (Bax).

\section{Discussion}

In our study, in the testicular tissue of newborn rat pups, we observed a decrease in the diameter of the tubules, and the area of the parenchyma with increasing area of the stroma and development of interstitial edema, caused by hypoxia of various geneses. The number of Leydig cells decreased in the tissues of the testicles of newborn rat pups only in the group of hemic hypoxia. Our studies are consistent with the studies of a number of authors, in which dystrophic and necrobiotic changes in the spermatogenic tubular epithelium were noted, as well as sclerotic changes and a decrease in the number of Leydig cells under the influence of hypoxia $[3,8]$.

In the tissues of the testicles of mature rats, who underwent antenatal hypoxia, a decrease in the diameter of the tubules, a significant decrease in the spermatogenesis index and a decrease in the number of spermatogonia were observed, which is in full agreement with the results of studies by other authors on the effect of oxidative stress of various etiologies on the development of testicular dysfunction $[3,8,9]$.

It is known, that fibroblast growth factor receptors are involved in the processes of angiogenesis, embryogenesis, tissue regeneration. A study by Lucía Saucedo et al. (2015) reports a positive effect of receptors of fibroblast growth factor on sperm motility [10].

In our work, we observed damage to the spermatogenic epithelium in experimental groups of newborns and mature males, which was confirmed by pronounced expression of the apoptosis marker (Bax), weak expression of proliferation markers (Ki67) and receptor of fibroblast growth factor (FGFR).

In a previous work [4], at immunohistochemical study, we noted a decrease in the proliferative potential and an increase in the expression of the apoptosis marker in gonocytes, Sertoli and Leydig cells in the offspring of rats with normobaric hypoxia. In the present study, we observed this trend in adulthood as well. Hemic hypoxia caused effects similar to those caused by normobaric hypoxia, but the degree of damage to the spermatogenic epithelium was higher.

\section{Conclusion}

Based on the foregoing, it can be concluded that in animals with chronic hypohia of various origins the inhibition of spermatogenesis takes place, which is reliably confirmed by both generally accepted morphometric methods and specific immunohistochemical research methods. After antenatal hypoxia in the testes of mature individuals the generative dysfunction is detected, as evidenced by the decrease in expression of proliferation marker Ki67 and receptor of fibroblast growth factor, and an increase in expression of apoptosis marker Bax.

Conflict of interest

None declared.

\section{References}

1. Fainberg J, Kashanian JA. Recent advances in understanding and managing male infertility. F1000Res 2019 May 16; 8: F1000 Faculty Rev-670. https://doi.org/10.12688/f1000research.17076.1

2. Hutter D, Kingdom J, Jaeggi E. Causes and mechanisms of intrauterine hypoxia and its impact on the fetal cardiovascular system: a review. Int $J$ Pediatr 2010; 2010: 401323. https://doi.org/10.1155/2010/401323.

3. Reyes JG, Farias JG, Henríquez-Olavarrieta $S$, Madrid E, Parraga M, Zepeda $A B$, et al. The hypoxic testicle: physiology and pathophysiology. Oxid Med Cell Longev 2012; 2012: 929285. https://doi.org/10.1155/2012/929285.

4. Palatova TV, Bucharskaya AB, Medvedeva AV, Voronina ES, Maslyakova GN. Influence of chronic intrauterine hypoxia on development of testicles of newborns. Russ Open Med J 2018; 7: e0201. https://doi.org/10.15275/rusomj.2018.0201.

5. Manual on experimental (preclinical) study of new pharmacological substances. Khabriev RU, Ed. Moskow, Russia: Medicine. 2005; 835 p. Russian. https://elibrary.ru/item.asp?id=19116235.

6. The guide to laboratory animals and alternative models in biomedical researches. Karkishchenko NN, Grachev SV, Eds. Moskow, Russia: Profile, 2010; 358 p. https://elibrary.ru/item.asp?id=23787521. 
7. Sosedova LM, Vokina VA, Rukavishnikov VS. Patent RU No. 2497202. Method for simulating prenatal hypoxic encephalopathy in small laboratory animals. Bull. No. 30. Published October 27, 2013. Russian.

8. Sizonenko ML. Bryukhin GV, Laskov DS. Peculiarities of morphofunctional development of the testis in the offspring of female rats with chronic liver injury of various genesis. Morphologiya 2012; 141(3): 142. Russian. https://elibrary.ru/item.asp?id=18484894.

9. Hwang GS, Wang SW, Tseng WM, Yu CH, Wang PS. Effect of hypoxia on the release of vascular endothelial growth factor and testosterone in mouse TM3 Leydig cells. Am J Physiol Endocrinol Metab 2007; 292(6): E1763-E1769. https://doi.org/10.1152/ajpendo.00611.2006.

10. Saucedo L, Buffa GN, Rosso M, Guillardoy T, Góngora A, Munuce MJ, et al. Fibroblast Growth Factor Receptors (FGFRs) in Human Sperm: Expression, Functionality and Involvement in Motility Regulation. PLoS $\begin{array}{llll}\text { One. } & \text { 2015; } & \text { 10(5): } & \end{array}$ https://doi.org/10.1371/journal.pone.0127297.

\section{Authors:}

Tatiana V. Palatova - MD, Instructor, Department of Pathologic Anatomy, Saratov State Medical University, Saratov, Russia. https://orcid.org/00000002-3889-5052.

Alla B. Bucharskaya - PhD, Head of the Center of Collective Use, Research Institute of Fundamental and Clinic Uronephrology, Saratov State Medical University, Saratov, Russia. https://orcid.org/0000-0003-0503-6486.

Anna V. Medvedeva - MD, Senior Lecturer, Department of Pathologic Anatomy, Saratov State Medical University, Saratov, Russia. https://orcid.org/0000-0001-6548-0955.

Elena S. Voronina - MD, Senior Lecturer, Department of Pathologic Anatomy, Saratov State Medical University, Saratov, Russia. https://orcid.org/0000-0002-4954-4784.

Svetlana S. Pakhomy - MD, Senior Lecturer, Department of Pathologic Anatomy, Saratov State Medical University, Saratov, Russia https://orcid.org/0000-0002-8540-6901.

Galina N. Maslyakova - MD, DSc, Professor, Head of Department of Pathologic Anatomy, Saratov State Medical University, Saratov, Russia. https://orcid.org/0000-0001-8834-1536. 